\title{
POR UMA RACIONALIDADE AMBIENTAL: REFLEXÕES ACERCA DOS REGRAMENTOS PROPOSTOS PARA PESCA DA TAINHA NO ESTUÁRIO DA LAGOA DOS PATOS/RS
}

Tatiana Walter ${ }^{1}$, Liandra Peres Caldasso ${ }^{2}$, Jéssica Fischer ${ }^{3}$ e Ivanilda Foster Almeida ${ }^{4}$

\section{RESUMO}

As reflexões aqui expostas versam sobre a contribuição do Estado, apoiado no discurso científico predominantemente da biologia pesqueira, cujas regulações ambientais têm como premissa uma visão dicotômica entre sociedade e ambiente. Ao não reconhecerem outras racionalidades na relação com 0 ambiente, as normativas nada mais são do que mecanismos promotores de conflitos ambientais. Nossa análise tem como suporte as normativas em vigor com vistas à gestão da pesca da tainha no sudeste e sul do Brasil, em especial, no estuário da Lagoa dos Patos/RS. Verificamos que as proposições se dão em uma perspectiva biologicista e estado-centrada que, ao mesmo tempo em que, inviabilizam a manutenção dos modos de vida dos pescadores(as) artesanais desta região,dão sustentação a uma pesca industrial destinada ao mercado externo.

Palavras-chaves: pesca artesanal, conflitos ambientais, gestão pesqueira, tainha, Lagoa dos Patos/RS.

\section{ABSTRACT}

The reflections presented here discuss the contribution of the Statein environmental regulations, supported by the scientific discourse predominantly of fisheries biology, that have as premise a dichotomous vision between society and environment. By not recognizing other rationalities in relation to the environment, the regulations are nothing more than mechanisms that promote environmental conflicts. Our analysis is based on current regulations for the management of mullet fisheries in the southeast and south of Brazil, especially in the estuary of Patos Lagoon/RS. We have verified that the propositions take place in a biologicist and state-centered perspective that, at the same time, make it impossible to maintain the livelihoods of the artisanal fishers of this region, and give support to an industrial fishing destined to the external market.

Key-words: artisanal fisheries, environmental conflicts, fisheries management, mullet, Patos Lagoon / RS.

\footnotetext{
${ }^{1}$ Oceanóloga, Doutora em Ciências Sociais - UFRRJ. Pesquisadora do Programa de PósGraduação em Gerenciamento Costeiro - FURG, Campus São Lourenço do Sul/RS.

${ }^{2}$ Economista; Doutora em Políticas Públicas - UFRJ. Professora do Curso de Gestão de Cooperativas - ICEAC/FURG, Campus São Lourenço do Sul.

${ }^{3}$ Tecnóloga em Gestão Ambiental; Mestre em Gerenciamento Costeiro - FURG.

${ }^{4}$ Tecnóloga em Gestão Ambiental; Mestre em Gerenciamento Costeiro - FURG.
} 


\section{Introdução}

As análises científicas em torno dos conflitos ambientais têm revelado a preponderância de uma racionalidade que compreende a relação entre sociedade e ambiente como dicotômica, ao mesmo tempo em que, assume que a problemática ambiental se deve principalmente a escassez dos recursos (LEFF, 2006). Ou seja, prepondera uma compreensão "cuja perspectiva malthusiana limita-se a compreender o ambiente na relação quantitativa entre população e território ou entre crescimento econômico e base finita de recursos" (ACSELRAD, 2004, p. 13).

Consequentemente, instrumentos de mercado, tecnologia e instituições são compreendidos como suficientes para equacionar os problemas ambientais. Nesta visão, definida como paradigma da adequação tecnológica, verifica-se mecanismos que enrustidos do debate sobre sustentabilidade viabilizam normativas e regulações que culminam na expropriação de comunidades tradicionais.

Os críticos dessa abordagem, a exemplo de Leff (2006) e Acselrad (2004), apontam os limites em torno deste paradigma. Para estes, a problemática ambiental é parte da crise civilizatória que é pautada pela acumulação do lucro, fato que resulta no consumo exacerbado do ambiente e de sua poluição, culminando em uma desigualdade ambiental. Na modernidade atual, ciência e tecnologia atuam sobre uma perspectiva de artificialização da natureza, cuja racionalidade nega culturas e resulta na separação entre sociedade e ambiente (LEFF, 2006).

Nesta perspectiva, a construção do conhecimento hegemônico, demarcado pela ciência e pela tecnologia, transforma-se em instrumento de poder, sendo decisivo na desestruturação de ecossistemas. Para Leff (2006) faz-se necessário a busca por outra racionalidade, a racionalidade ambiental.

As mestiçagens culturais havidas ao longo da história da humanidade fundiram códigos genéticos e códigos de linguagem através das diversas formas culturais de significação e apropriação cultural da natureza. A racionalização econômica do mundo, fundada no projeto científico da modernidade, chegou a esquadrinhar os números mais íntimos da natureza, até fazer explodir a energia do átomo, descobrir os buracos negros do cosmo e penetrar o código genético da vida. Ao longo da história, as cosmovisões e as formas de conhecimento do mundo criaram e transformaram o mundo de diversas maneiras. Mas o que há de inédito na crise ambiental do nosso tempo é a forma e o grau em que a racionalidade da modernidade vem intervindo no 
mundo, socavando as bases da sustentabilidade da vida e invadindo os mundos de vida das diversas culturas que conformam a raça humana, em uma escala planetária (LEFF, 2006, p. 17).

É no paradigma da sustentabilidade, cujos saberes e culturas são compreendidos como manifestações da natureza, é que autores como Leff (2006) e Acselrad (2004) apontam a superação da dicotomia sociedadeambiente. A regulação ambiental ${ }^{5}$, a despeito de sua importância reconhecida, necessita ser reconstruída sobre outra perspectiva, sobre outras racionalidades, caso deseje lograr êxito. Dentre as distintas formas de conflitos ambientais que recrudescem atualmente, parte deles ocorre no contexto das políticas ambientais.

É no campo simbólico que estão situados os conflitos ambientais envolvendo os regramentos ambientais, uma vez que é por meio do Estado que o discurso científico evoca uma definição de "natureza estatizada, integrada ao capital e de uma natureza residual onde acomodam-se os agentes que resistem e/ou são excluídos espacialmente" (ACSELRAD, 2004, p. 21).

A legitimidade desta determinação estatal das condições de reprodução dos ecossistemas baseia-se com frequência na ciência: as lutas sociais envolvendo meio ambiente tendem, em consequência, a ser despolitizada pela cientifização das políticas ambientais, sendo a própria despolitização, por certo, uma estratégia de afirmação da distribuição de poder no campo de forças. Assim é que as agências estatais de meio ambiente, sustenta Fabiani ${ }^{6}$, limitam-se por vezes, a ação simbólica de administrar as representações de Natureza, separando a Natureza a conservar da Natureza ordinária, aberta a apetites econômicos (ACSELRAD, 2004, p. 21).

É no debate sobre o papel do Estado, em contribuição com o conhecimento científico centrado na biologia pesqueira, que se situam nossas reflexões acerca dos conflitos oriundos da atual proposta de ordenamento pesqueiro da tainha nas zonas costeira e marinha brasileira. Não apenas por se tratar desta disciplina - biologia pesqueira - mas por se organizar sobre uma lógica disciplinar e que não reconhece outras racionalidades, que podem

\footnotetext{
${ }^{5}$ Normativas e regulações ambientais dizem respeito aos regramentos destinados ao uso dos recursos ambientais. Por meio deles, o Estado define quem, quando, quanto e como se utiliza um determinado recurso, estabelecendo por meio disto a legitimidade de determinados grupos em relação ao acesso ao ambiente. Sob uma perspectiva discursiva, tais regramentos legitimam quem é portador de uma dada sustentabilidade e quem não o é (ACSELRAD, 2010). ${ }^{6} \mathrm{O}$ autor se refere a J.L. Fabiani "La Nature, I'Action Publique et La Régulation Sociale", in N. Mahieu, M. Jollivet (Ed.). Du Rural à Environmentm Ed. L'Harmattan, 1989, p. 195-208.
} 
ser presentes também em outros campos do conhecimento que subsidiam o regramento ambiental.

Nossas análises destinam-se a compreender as consequências desta racionalidade para os modos de vida dos pescadores artesanais do estuário da Lagoa dos Patos, no Rio Grande do Sul e, na ação dos mesmos com vistas ao enfrentamento acerca dos regramentos propostos pelo "Plano de Gestão para o Uso Sustentável da Tainha, Mugil liza ${ }^{7}$ Valenciennes, 1836, no Sudeste e Sul do Brasil" aprovado por meio da Portaria MPA/MMA n ${ }^{\circ} 03$, de 14 de Maio de 2015 (BRASIL, 2015).

\section{A contextualização da pesquisa na ação}

A pesquisa em tela tem como referência nossa atuação enquanto integrantes da Universidade junto ao Fórum da Lagoa dos Patos ${ }^{8}$.Nossa participação nesta instância data do início de 2015 de forma recorrente. Em síntese, participamos de sua rotina, envolvendo reuniões e diálogos com as lideranças pesqueiras que coordenam o Fórum, de suas reuniões ordinárias mensais e daquelas extraordinárias. Também atuamos na assessoria técnica relacionadas às questões ambientais conforme demandas dos próprios pescadores.

Assim, quando da constatação da vigência do plano de gestão para pesca da tainha prevista para o estuário da Lagoa dos Patos a partir de março de 2017, lideranças e pescadores(as), durante a reunião ordinária de 29/09/2016na Colônia de Pescadores Z-01 em Rio Grande/RS, explicitaram a

\footnotetext{
${ }^{7}$ Destaca-se que o documento que subsidia a definição dos regramentos para tainha faz referência apenas à espécie de tainha Mugil liza. Contudo, em seu conteúdo é evidenciado que atualmente M. lizae M. platanus são a mesma espécie. Assim, ainda que estejamos tratando da mesma espécie, optamos por ao longo deste artigo manter a nomenclatura utilizada na literatura consultada, fato que em alguns momentos iremos nos referir a uma ou a outra.

${ }^{8}$ O Fórum da Lagoa dos Patos foi criado em 1996 devido à crise pesqueira vivenciada no estuário da Lagoa dos Patos/RS na década de 1990. É parte do conjunto de experiências protagonizadas pelo IBAMA denominadas de Gestão Participativa e que foram delineadas pelo órgão devido à necessidade de maior diálogo e envolvimento do setor na proposição de medidas destinadas à gestão sustentável do uso dos recursos pesqueiros e está situado no bojo de experiências de participação no período de redemocratização do país. O Fórum da Lagoa dos Patos é ativo até hoje, realizando reuniões ordinárias mensais em quatro de seus cinco municípios de abrangência: Rio Grande, São José do Norte, Pelotas, São Lourenço do Sul e Tavares. Atualmente envolve a participação dos representantes dos pescadores artesanais, prefeituras, órgãos federais e estaduais que atuam no fomento e na conservação dos recursos pesqueiros, Universidades, Organizações Não-Governamentais, dentre outros.
} 
preocupação com o conteúdo do documento e com o desconhecimento acerca do mesmo pela maior parte dos(as) pescadores(as) da região. Este fato gerou a demanda, por parte da plenária, por subsidiá-los na leitura do plano, culminando na presente pesquisa. Assim, o objetivo de compreender os regramentos previstos e os impactos destes no cotidiano da pesca artesanal do estuário da Lagoa dos Patos foi traçado conjuntamente com os pescadores, que definiram como questões orientadoras, a compreensão sobre os efeitos da medida no exercício da pesca e na produção pesqueira. Um questionamento central era o fato do Fórum não ter participado de nenhum debate pretérito, dada sua existência desde 1996, do protagonismo do IBAMA quando de sua criação e, tanto deste como do Ministério da Pesca e Aquicultura - MPA, serem, teoricamente ${ }^{9}$, seus integrantes.

Para Freitas (2004, p. 151)

\begin{abstract}
Metodologias participativas como forma de fortalecer os laços comunitários de solidariedade, devem estar orientadas para 0 incremento do poder técnico e político das comunidades nos processos decisórios que afetam o nível local, reafirmando de forma radical a democracia nas relações sociais, políticas, econômicas e culturais, elementos fundamentais para sustentabilidade e justiça ambiental. Essas estratégias participativas devem fortalecer 0 pluralismo de poder no nível local, permitindo que a incorporação das diferentes perspectivas que derivam das formas comunitárias de vida possa vir a contrabalancear ou mesmo compensar o que Bauman denomina de potencial genocida adormecido nas capacidades instrumentais da modernidade.
\end{abstract}

A proposição da pesquisa na perspectiva da pesquisa-ação (THIOLLENT, 2007) não se resume a uma leitura acerca do documento. É relevante compreender os mecanismos que reverberam sobre o acesso dos(das) pescadores(as) aos recursos ambientais necessários a sua reprodução social, de forma que estes possam se posicionar nas arenas políticas que tratam da temática. Em consequência, a análise elaborada é fundamentada na Ecologia Política, área do conhecimento que se ocupa das questões distributivas em torno do ambiente. Em especial, faz uso dos preceitos da Justiça Ambiental, cujo debate deflagra que o acesso ao meio ambiente não tem sido equitativo:

\footnotetext{
${ }^{9}$ De fato, IBAMA e MPA possuem acento no Fórum da Lagoa dos Patos. Entretanto, desde 2015 a participação de ambos tem sido esporádica. O que temos verificado é que, desde 2009 quando inicia a proposta de gestão compartilhada entre Ministério do Meio Ambiente (MMA) e MPA, as decisões - ainda que conflitivas- tornam-se centralizadas entre esses atores. Assim, cada vez mais o Fórum tem se colocado nos debates como movimento social e não mais como instância de gestão, em virtude do esvaziamento das organizações públicas responsáveis por ela.
} 
AMBIENTE \& EDUCAÇÃO

ISSN- 1413-8638

E-ISSN - 2238-5533

v. 23, n. 1, p. 31-53, 2018

Por tratamento justo entende-se que nenhum grupo de pessoas, incluindo-se aí grupos étnicos, raciais ou de classe, deva suportar uma parcela desproporcional das consequências ambientais negativas, resultantes de operações industriais, comerciais e municipais, da execução de políticas e programas federais, estaduais, locais ou tribais, bem como, das conseqüências resultantes da ausência ou omissão dessas políticas (HERCULANO, 2008, p. 2).

Alguns fatores ideológicos têm contribuído para dificultar a percepção sobre a injustiça ambiental, dentre as quais está "o conservacionismo de uma corrente do movimento ambientalista que ignora as questões do universo da produção e que acredita que os problemas ambientais são democráticos por atingirem a todos, o que só é verdade em longo prazo quando, como lembrou Keynes, 'todos estaremos mortos'” (HERCULANO, 2008, p. 7).

Alguns dos princípios que são defendidos no campo da justiça ambiental versam sobre: i) o acesso justo e equitativo, direto e indireto, sobre os recursos ambientais do país; ii) amplo acesso às informações relevantes sobre o uso dos recursos ambientais e a destinação dos rejeitos assegurados por meio de processos participativos, democráticos na definição das políticas, planos, programas e projetos que the dizem respeito; iii) o favorecimento e a constituição de sujeitos coletivos e de direitos, movimentos sociais e organizações populares, a protagonizarem outras formas de vida, outros modos de desenvolvimento, ou seja, outra racionalidade na relação com o ambiente (HERCULANO, 2008). No debate em torno da justiça ambiental é relevante a ampliação da participação da sociedade na gestão dos recursos naturais, especialmente daqueles que são os mais afetados pelas decisões e comumente são alijados ou possuem maior dificuldade em participar. Tal dificuldade pode ser concebida sob uma perspectiva estrutural, ou seja, recursos financeiros e/ou tempo, mas também na relação do conhecimento, cuja condução sob uma perspectiva técnico-científica não dialoga ou inviabiliza a participação daqueles sujeitos que possuem outra racionalidade (UEMA, 2009).

Para atingir nossos objetivos focamos nossas análises em três dimensões dos regramentos propostos no âmbito do Plano: i) a(s) unidade(s) de gestão adotada(s); ii) o regime de propriedade e como o mesmo molda o processo decisório; iii) as características do ciclo de vida da tainha - elemento central do conjunto de regramentos propostos - associadas às características da pesca 
artesanal no estuário da Lagoa dos Patos/RS e da pesca industrial de tainha. No conjunto, temos como fito compreender como esse conjunto culmina em uma gestão pesqueira estado-centrada e na desigualdade ao acesso ao meio ambiente, de forma a contrapor uma visão científica que assume a'sustentabilidade independente daqueles que dependem do recurso para sua reprodução social e que compreende o conhecimento científico como inquestionável por outros entes da sociedade e como absoluto,10.

Os procedimentos de pesquisa adotados são oriundos da pesquisa social qualitativa. Além da análise do documento na íntegra, envolveram: i) revisão bibliográfica; ii) categorização e sistematização de entrevistas junto aos pescadores artesanais oriundas de pesquisas pretéritas cujas transcrições compõem um banco de dados sobre a pesca artesanal nos municípios estudados; iii) pesquisa-observante em participação em reuniões junto aos pescadores(as)artesanais e junto aos gestores públicos responsáveis pelo plano e aos cientistas que atuam na temática.

As entrevistas junto a 68 pescadores ocorreram em visitas às comunidades pesqueiras nos municípios de Rio Grande, São José do Norte, Pelotas e São Lourenço do Sul, realizadas entre maio e agosto de 2016. A pesquisa observante ocorreu por meio da participação em: i) reuniões do Fórum da Lagoa dos Patos no período de 2015 e 2017, incluindo a análise das atas; ii) reuniões com lideranças pesqueiras em janeiro de 2017 e; iii) reunião junto ao MAPA/MMA em março de 2017. As análises são realizadas a partir da técnica de triangulação de métodos, conforme Minayo et al. (2005).

Momento relevante foi à reunião extraordinária do Fórum da Lagoa dos Patos realizada em 26/01/2017 na Colônia Z-01 em Rio Grande, quando apresentamos as análises do Plano de Gestão da Pesca da Tainha. Esta reunião contou com a participação de 360 pessoas que assinaram a lista de presença, em sua maioria, pescadores e pescadoras artesanais.

\footnotetext{
${ }^{10}$ Ao longo das reuniões acerca do Plano, quando do debate em torno dos regramentos, as falas de alguns cientistas que participavam da proposta de regramentos explicitavam tais visões. Seja no sentido de que a sustentabilidade do recurso é independente da questão distributiva, ou seja, a sustentabilidade é do ambiente natural e não importa a questão social. Seja, no fato do conhecimento acerca dos estoques, envolvendo defeso, maturação etc. são inquestionáveis, pois são oriundos de um saber absoluto.
} 
ISSN- 1413-8638

E-ISSN - 2238-5533

v. 23, n. 1, p. 31-53, 2018

\section{A pesca artesanal no estuário da Lagoa dos Patos}

No Brasil, a despeito das dificuldades em relação à coleta de informações precisas sobre a produção pesqueira artesanal, há um consenso que sua contribuição é de aproximadamente $60 \%$ da produção total de pescado, destinado principalmente ao abastecimento interno.Para além de sua importância econômica, a pesca artesanal é também uma atividade tradicional, relevante na cultura do país e importante fornecedora de proteína nos municípios costeiros (DIEGUES \& ARRUDA, 2001).

$\mathrm{Na}$ pesca artesanal, a unidade produtiva é a família, envolvendo seus integrantes no processo de captura, beneficiamento, confecção de petrechos de pesca, sendo o processo produtivo organizado pelo saber-fazer. Sua dinâmica é influenciada pelo mercado, contudo, a lógica não é da reprodução do capital, mas da reprodução ampliada da vida (DIEGUES, 1983).

Apesar de sua relevância, segundo a Food Agriculture Organization FAO (2016), nas últimas décadas a pesca artesanal convive com um processo crítico de declínio de sua produção, oriundo da degradação ambiental e da sobrepesca, resultantes de processo de ocupação desordenada, poluição e pesca predatória. A despeito de um conjunto de normativas destinado à sua regulação, denominadas em seu conjunto de gestão pesqueira, mantém-se a condição de precariedade da atividade e dos pescadores e pescadoras artesanais que dela dependem.

No estado do Rio Grande do Sul, a maior concentração de pescadores artesanais reside nos municípios adjacentes ao estuário da Lagoa dos Patos. São 4.089 pescadores(as)artesanais atuantes na etapa da captura e outros(as) 3.259 que participam dos demais elos da cadeia produtiva, envolvendo a manutenção de equipamentos,limpeza, processamento e comercialização do pescado, distribuídos(as) nos seguintes municípios: São José do Norte, Pelotas, Tavares, Mostardas, São Lourenço do Sul, Tapes, Arambaré e Camaquã (KALIKOSKI \& VACONCELLOS, 2013) ${ }^{11}$. Conforme dados do

\footnotetext{
${ }^{11}$ Destaca-se que os autores consideram pescadores artesanais as pessoas envolvidas apenas com a etapa da captura. Enquanto, para os mesmos, as atividades de apoio à pesca destinam-se aqueles que atuam nas demais etapas da cadeia produtiva. Por discordarmos dessa definição - dada a pesca artesanal ser uma atividade familiar que envolve a divisão de trabalho na família para obtenção de um produto final destinado tanto a manutenção produtiva como reprodutiva, ou seja, pescadores artesanais são homens e mulheres envolvidos no
} 
escritório do IBAMA em Rio Grande, 2.895 pescadores (as) artesanais atuantes na etapa de captura - solicitaram licença ambiental em 2016, sendo 98\% dos pescadores de São José do Norte (43\%), Rio Grande (27\%), Pelotas $(23 \%)$ e São Lourenço do Sul $(5 \%)^{12}$.

Dentre as mais de 110 espécies de peixes e crustáceos que existem neste estuário, Kalikoski \& Vasconcellos afirmam quatro como importantes na formação da renda para a pesca artesanal há mais de um século: camarãorosa Farfantepenaeus paulensis, tainha Mugi Iplatanus, corvina Micropogonias furnieri e bagre Genidens barbus. Enquanto, o camarão, a tainha e a corvina constituem-se espécies de importância relativa principal, o bagre tem sua importância relativa secundária (FURG 2012, 2013a, 2013b, 2014, 2015).

Tainha e corvina são capturas que respondem pela formação da renda ao longo do ano, enquanto boas safras de camarão resultam em um acréscimo de renda que permite investimentos nas pescarias ou junto às famílias. Apenas a tainha, em peso, correspondeu entre $17 \%$ a $36 \%$ da captura total anual entre os anos de 2012 e 2015 no estuário (Tabela1).

Já o bagre, o linguado, siri, peixe-rei e outras espécies - incluindo espécies de água doce - tornam-se importante quando há safras fracassadas, resultantes de períodos chuvosos intensos. Para Kalikoski \& Vasconcellos (2013) essas espécies minimizam a vulnerabilidade dos pescadores quando de adventos climáticos extremos. Condição bastante explicitada nos últimos quatro anos devido à predominância de água doce na Lagoa, fato que diversas das safras principais foram fracassadas.

\section{Tabela 1 - Relação entre a produção, em toneladas/ano, de tainha e total, capturadas pela pesca artesanal no estuário da Lagoa dos Patos - RS}

processo produtivo como um todo e não apenas na captura, readequamos a nomenclatura utilizada pelos autores.

12 Dados analisados pelas autoras a partir da planilha protocolada junto ao Fórum da Lagoa dos Patos pelo IBAMA na Reunião Ordinária de 29/09/2016 em Rio Grande, contendo o detalhamento dos dados dos pescadores que solicitaram licença ambiental em 2016. Destacase, aqui, que a licença de pesca é concedida ao pescador (em geral homem) que atua na captura, uma vez que a regulação ambiental volta-se ao controle do esforço de pesca. Tal proposição tem resultado em conflitos de gênero envolvendo o ordenamento pesqueiro no estuário da Lagoa dos Patos conforme exposto por Hellebrandt et al. (2016), dado que as licenças concedidas às mulheres são tratadas como uma exceção. Em nosso caso, desejamos apenas evidenciar o número de pessoas na captura com vistas a explicitar a maior concentração de pescadores(as) artesanais nos municípios pesquisados, mas consideramos relevante demarcar os conflitos de gênero presentes por este modelo de gestão. 


\begin{tabular}{|c|c|c|c|}
\hline & Captura Total & Captura de Tainha & $\%$ \\
\hline 2012 & 2003,113 & 696,434 & $35 \%$ \\
\hline 2013 & 2869,998 & 780,579 & $27 \%$ \\
\hline 2014 & 1268,263 & 216,212 & $17 \%$ \\
\hline 2015 & 1404,971 & 501,159 & $36 \%$ \\
\hline
\end{tabular}

Fonte: Adaptado dos Boletins de Estatística da FURG (2012, 2013a, 2013b, 2014, 2015).

Não obstante, tal vulnerabilidade torna-se maior, quando os regramentos ambientais desconsideram a dependência dos pescadores artesanais ao ambiente, bem como, as variações ambientais como elementos que integram suas estratégias de manutenção econômica. Há uma interdependência dos pescadores em relação às diversas espécies e a sua presença a partir da hidrodinâmica do estuário: $O$ sal é que traz a vida para lagoa, diz um dos entrevistados. A importância de cada espécie pode ser diferenciada de um ano para outro, por comunidade e por pescador, característica comum de pescarias artesanais multiespecíficas.

Consequentemente, mecanismos de ordenamento para uma espécie, elaborados isoladamente podem gerar maior pressão e conflitos sobre outros recursos, preocupação que não é apontada ao longo da proposição do Plano de Gestão da Pesca da Tainha e, que de maneira geral, encontrava-se equacionada no âmbito da Instrução Normativa Conjunta entre MMA/SEAP IN n⿳03/2004 (BRASIL, 2004). Esta normativa - a despeito de opiniões adversas sobre sua efetividade - foi elaborada com a participação dos pescadores(as) artesanais do estuário e propõe o ordenamento do conjunto de espécies de interesse econômico. Dentre outros aspectos, a IN buscou equacionar a presença recorrente de pescadores de outras regiões - em especial de Santa Catarina - e foi estruturada com vistas a mediar os conflitos gerados entre pescadores locais e de fora, reconhecendo o estuário como território dos pescadores(as) ali residentes. Tal IN foitotalmente ignorada ao longo da nova proposta de regulação.

No que tange à produção total de tainha, as análises dos últimos anos demonstram uma forte influência sazonal, demarcada por uma maior produtividade nos meses entre março e maio, havendo picos em janeiro para os anos de 2012 e 2013 e em outubro para o ano de 2013 (Figura 1). 
Do ponto de vista econômico, a pesca artesanal também se revela importante regionalmente:

O valor total da produção pesqueira em uma boa temporada de pesca varia de aproximadamente $R \$ 23$ milhões a $R \$ 46$ milhões por ano, dependendo dos preços de primeira venda usados no cálculo. Isso representa menos de $1 \%$ do PIB dos municípios da região. Os municípios com os maiores resultados econômicos são: São José do Norte (R\$16.123 milhões, no cenário de maior preço), Rio Grande (R\$13.268 milhões) e Pelotas ( $\mathrm{R} \$ 11.630$ milhões). [...] As pescarias representam entre 3.0 e $6.0 \%$ do PIB da agricultura na região (KALIKOSKI \& VASCONCELLOS, 2013, p.81-82) ${ }^{13}$.

Figura 1 - Captura de tainha (em $\mathrm{Kg}$ ) pela pesca artesanal no estuário da Lagoa dos Patos entre 2012 e 2015

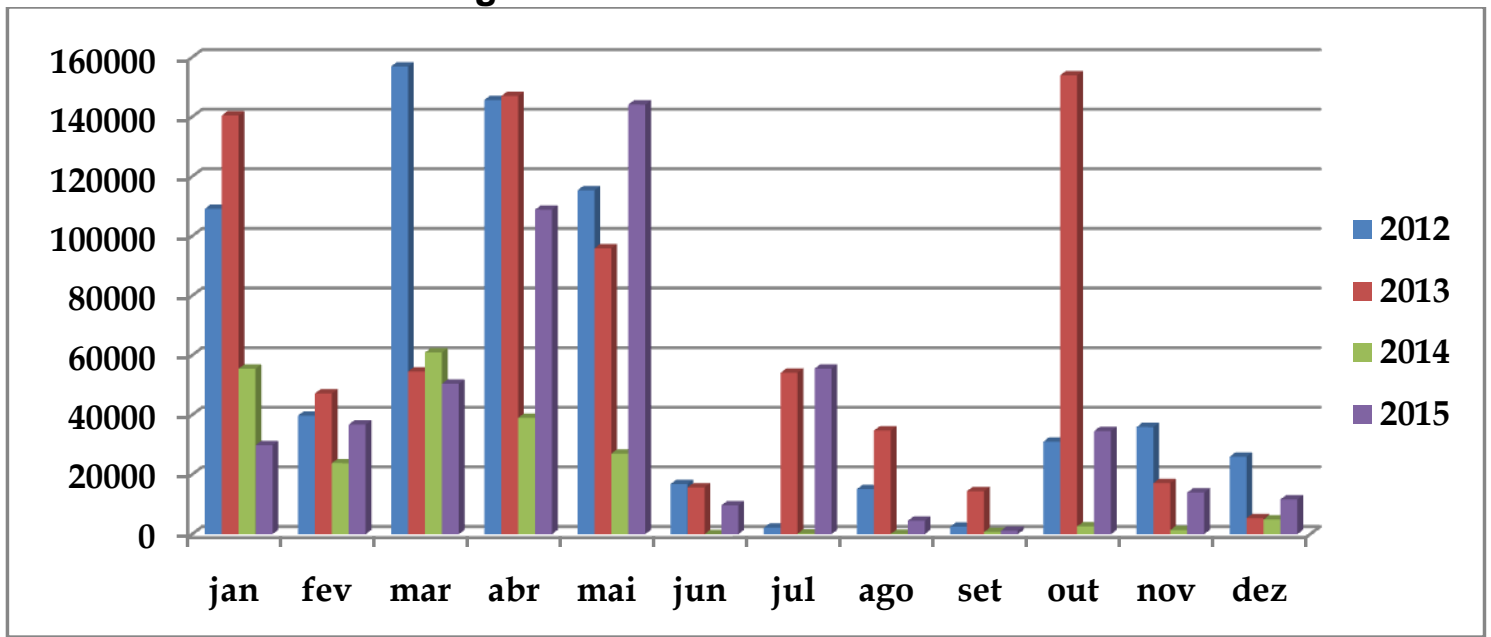

Fonte: Adaptado de FURG (2012; 2013a; 2013b; 2014; 2015).

Para Kalikoski \& Vasconcellos (2013), esses números representam um valor econômico subestimado do total da pescaria na região. Uma avaliação adequada exigiria dados mais exatos sobre a renda econômica e o valor agregado quando o peixe é vendido do pescador para o consumidor.

\section{Uma gestão que ignora a racionalidade ambiental}

O Plano de Gestão para o Uso Sustentável da Tainha Mugi liza,Valenciennes, 1836, no Sudeste e Sul do Brasil, publicado em abril de 2015, é um documento institucional de 238 páginas, de responsabilidade do Ministério do Meio Ambiente - MMA e do Ministério da Pesca e Aquicultura -

\footnotetext{
${ }^{13} \mathrm{Em}$ 2010, quando da coleta de informações por KALIKOSKI \& VASCONCELLOS (2013), o dólar valia $\mathrm{R} \$ 1,70$.
} 
AMBIENTE \& EDUCAÇÃo

ISSN- 1413-8638

E-ISSN - 2238-5533

v. 23, n. 1, p. 31-53, 2018

MPA $^{14}$, que conforme Decreto ํㅡ 6.981, de 13 de outubro de 2009, possuem atribuição compartilhada sobre a gestão dos recursos pesqueiros no Brasil (BRASIL, 2009).

Para as análises em fito, destacamos três dimensões do plano: i) unidade de gestão adotada; ii) regime de propriedade; iii) efeitos do regramento considerando o ciclo de vida da espécie e as características da pesca artesanal no estuário da Lagoa dos Patos/RS e da frota industrial catarinense. Um quadro completo contendo uma síntese do plano foi elaborado de forma a gerar subsídios às nossas reflexões (Quadro 1).

Quadro 1 - Síntese do Plano de Gestão o Uso Sustentável da Tainha Mugi liza,Valenciennes, 1836, no Sudeste e Sul do Brasil.

\begin{tabular}{|c|c|}
\hline & Síntese \\
\hline Informações Gerais & $\begin{array}{l}\text { Responsabilidade: Ministério da Aquicultura e Pesca - MPA; } \\
\text { Ministério do Meio Ambiente - MMA; Data de Publicação: Abril de } \\
2015 \text {. }\end{array}$ \\
\hline $\begin{array}{l}\text { Apresentação e } \\
\text { Antecedentes }\end{array}$ & $\begin{array}{l}\text { Destaca a importância econômica, social, cultural e para promoção } \\
\text { da segurança alimentar da pesca de tainha para o país, bem como, } \\
\text { a situação de sobrepesca e de aumento da vulnerabilidade da } \\
\text { espécie nos últimos anos devido, principalmente, à concessão de } \\
\text { licenças (permissionamento) para a frota pesqueira industrial de } \\
\text { cerco pelo MPA, a despeito das medidas de ordenamento pesqueiro } \\
\text { definidas pelo MMA. Aponta o histórico conflituoso entre os entes } \\
\text { que possuem atribuição na gestão e a mediação feita pelo Ministério } \\
\text { Público Federal de Rio Grande/RS que estabelece o prazo de } \\
\text { publicação do plano para } 2014 \text {. }\end{array}$ \\
\hline Institucionalidade & $\begin{array}{l}\text { Lei } n^{\circ} 11.958 \text {, de } 29 \text { de junho de } 2009 \text { que cria o Ministério da Pesca } \\
\text { e Aquicultura - MPA e estabelece a gestão compartilhada entre } \\
\text { MMA e MPA. }\end{array}$ \\
\hline Base Legal & $\begin{array}{l}\text { Leis e Decretos: Política Nacional de Desenvolvimento Sustentável } \\
\text { da Aquicultura e Pesca (Lei 11.959/2009) e Política Nacional de } \\
\text { Meio Ambiente (Lei n } 6.938 / 1981 \text { ); Convenções: Convenção das } \\
\text { Nações Unidas para o Direito do Mar; A Resolução da Assembleia } \\
\text { Geral das Nações Unidas sobre Descartes e "Bycatch" nas } \\
\text { pescarias e seu impacto sobre o uso sustentável dos recursos vivos } \\
\text { marinhos; o Código de Conduta para a Pesca Artesanal (FAO); A } \\
\text { Declaração e o Plano de Ação de Kioto, aprovados pela Conferência } \\
\text { Internacional sobre a Contribuição da Pesca Sustentável para a } \\
\text { Segurança Alimentar; a Convenção da Diversidade Biológica (CDB). }\end{array}$ \\
\hline $\begin{array}{c}\text { Regime de } \\
\text { Propriedade dos } \\
\text { Recursos Pesqueiros }\end{array}$ & c \\
\hline Unidade de Gestão & $\begin{array}{l}\text { Zona costeira e marinhas situadas entre o estado do Espírito Santo } \\
\text { e o Rio Grande do Sul, envolvendo todos os tipos de pescarias } \\
\text { existentes que possuem a tainha como alvo. }\end{array}$ \\
\hline Diagnóstico & $\begin{array}{l}\text { Evidencia a importância da inter e multidisciplinaridade, no entendo } \\
\text { a maior parte das análises são de cunho biológico-pesqueiro. }\end{array}$ \\
\hline
\end{tabular}

${ }^{14}$ Destaca-se que em 2015 o MPA é extinto, sendo suas atribuições repassadas ao Ministério da Agricultura, Pecuária e Abastecimento - MAPA. Em 2017, a pesca artesanal passou a ser de responsabilidade do Ministério da Indústria, Comércio Exterior e Serviços - MDIC. Atualmente há um limbo institucional acerca da pasta, o que contribui ainda mais para as incertezas associadas à gestão pesqueira no país. 


\begin{tabular}{|l|l|}
\hline & Demais aspectos são superficiais e descritivos. Apresenta a \\
distribuição da espécie conforme estágio de vida. Caracteriza, de \\
forma sintética, a pesca artesanal nos estados do Espírito Santo, Rio \\
de Janeiro, São Paulo, Paraná, Santa Catarina e Rio Grande do Sul. \\
Caracteriza em um item a parte a pesca industrial. De forma geral, \\
desconsidera regramentos locais/regionais e instâncias de gestão \\
pesqueira regionais ou locais, a exemplo do Fórum da Lagoa dos \\
Patos. \\
Abordagem sistêmica é restrita às questões oceanográficas e \\
climáticas, sem considerar os impactos de outras atividades \\
econômicas no ambiente. Não considera produção científica recente \\
sobre o estuário da Lagoa dos Patos. \\
\hline Prognóstico & $\begin{array}{l}\text { São apresentados quatro cenários. O primeiro propõe a proibição de } \\
\text { qualquer modalidade de pesca em cinco anos; o quarto propõe não } \\
\text { realizar nenhuma medida. O segundo e terceiro cenários são } \\
\text { intermediários, sendo a proposição dos gestores a implementação } \\
\text { do segundo. }\end{array}$ \\
\hline
\end{tabular}

Fonte: Resumo elaborado pelos autores, a partir de MPA; MMA (2015).

Sobre a primeira dimensão da análise, a unidade de gestão, tem-se:

A pesca de tainha (Mugil liza), nas suas diversas modalidades (artesanal e industrial) e ambientes (estuarino-lagunar e marinho), realizada nas regiões Sudeste e Sul, e considerando a existência de duas subpopulações para a espécie nesta unidade de gestão: (i) uma que ocorre do Rio Grande do Sul, até o limite norte de São Paulo (estoque sul) e; (ii) outra que se distribui desde o Rio de Janeiro até o norte do país (estoque norte) [...] ( MPA; MMA, 2015, p. 22).

Os regramentos propostos voltam-se, portanto, às regiões sudeste e sul (estoque sul), fato que tanto o diagnóstico como o prognóstico estão orientados a tais pescarias. A proposição desta unidade de gestão tem como referência científica a distribuição da espécie, em detrimento de uma abordagem que compreenda as características da pesca a partir da organização do processo produtivo, da tradicionalidade e de outros saberes. É na espécie - e em suas características biológicas - que são estabelecidas as premissas para definição dos mecanismos de regulação propostos. Demarca-se, aqui, esta área do conhecimento: a biologia, bem como, o predomínio de uma racionalidade científica que ignora outros saberes, excluindo também outras áreas do próprio conhecimento científico.

Deflagramos, nesta unidade de gestão, uma perspectiva científica que compreende eficiência por meio de regramentos similares para zona costeira e marinha em seis estados brasileiros. Qualquer participação social no processo decisório torna-se limitada pela necessidade de pensar a gestão para toda esta área, prevalecendo regramentos de larga escala, que devem servir a todos, em 
detrimento de acordos locais. Ignoram-se territórios pesqueiros, cultura e tradicionalidade dos diversos núcleos de pescadores artesanais situados ao longo da costa.

Concepção que reforça uma política ambiental tecnicista, disciplinar, que despolitiza as questões ambientais e não reconhece outras racionalidades e outras áreas da ciência. Qualquer especificidade torna-se de importância menor, pois o recurso pesqueiro é uno, universal e seu ciclo de vida necessita ser preservado.

A participação social torna-se de menor relevância, as demandas dos sujeitos alvos deste regramento são invisíveis. Somente aqueles que têm expressão nacional - a indústria pesqueira, por meio de sua capacidade política $^{15}$, econômica ou simplesmente por deter este imenso território marinho - participam do processo de negociação.

Assim, o plano ignora completamente qualquer regramento e experiência localizada em áreas menores, com identidades culturais como é o caso do estuário da Lagoa dos Patos (Quadro 1). Segundo os responsáveis por sua implantação, são regramentos locais, insuficientes e que não tem sido capazes de regular adequadamente às pescarias, dado a situação de expansão da frota industrial, que foi promovida pelo próprio Estado brasileiro e que atua na área marinha. Argumentos estes que são utilizados para fundamentar uma decisão estado-centrada, ancorada estritamente no conhecimento científico.

A segunda dimensão analisada foi o regime de propriedade dos recursos pesqueiros: a propriedade estatal (Quadro 1). Tal regime estabelece a atribuição do Estado na definição dos regramentos sobre o ambiente e orienta princípios constitucionais dos recursos enquanto bem da coletividade, conforme o Artigo 225 da Constituição Federal de 1988 (BRASIL, 1988). Entretanto, os argumentos científicos acerca do regime estatal o confundem com regime de propriedade aberta, sob alegação que o Estado não possui mecanismos eficientes para sua regulação.

\footnotetext{
${ }^{15}$ Azevedo \& Pierri (2014) ao analisarem a política pesqueira no Brasil no período de 2003 a 2011 deflagram que o Decreto-Lei 6.981/2009 (BRASIL, 2009) demarca o ordenamento pesqueiro pelo órgão setorial, prevalecendo suas decisões em detrimento da área ambiental. As autoras apontam o não cumprimento tanto da SEAP/PR, em período anterior, como do MPA quando do estabelecimento do limite das embarcações pesqueiras para pesca de sardinhaverdadeira e da tainha, explicitando o forte poder da indústria pesqueira nas regulações ambientais.
} 
Há uma defesa sobre a questão da propriedade como fator preponderante na problemática ambiental. Ou seja, apoiada na Tragédia dos Comuns de Garret Hardin, elaborada em 1968, argumenta-se que, por um lado, toda e qualquer pessoa pode acessar o recurso pesqueiro, não reconhecendo 0 conhecimento tradicional como mecanismo necessário ao saber-fazer que estabelece o sucesso da pescaria, tampouco regimes de propriedade comunitários, característicos de comunidades tradicionais como defende Elinor Ostrom em diversos trabalhos.

Soma-se a perspectiva da Tragédia dos Comuns, a visão de que os pescadores são dotados de um comportamento egoísta que orienta à maximização dos lucros, o que culminará no esgotamento inevitável dos recursos pesqueiros. Marcada por um viés malthusiano, os defensores desta visão apontam os mecanismos de mercado como única saída para a gestão pesqueira. Nesta perspectiva tem-se no pescador um predador perfeito. Independente da pesca industrial ser organizada com vistas à acumulação do lucro e a artesanal predominantemente pela reprodução social (DIEGUES, 1983), ambas são semelhantes sob essa perspectiva. Consequentemente, no ordenamento da tainha a solução para sustentabilidade está ancorada na alteração do regime de propriedade, de estatal para privado, que no caso da atividade pesqueira, é defendida pelos cientistas pesqueiros por meio do sistema de $\operatorname{cotas}^{16}$.

Corrobora ao regime de propriedade o predomínio de uma abordagem que restringe o foco da gestão para a relação entre a captura e o pescador, fato que todos os demais fatores que contribuem à degradação dos oceanos e estuários e na diminuição da produtividade pesqueira tornam-se externalidades ${ }^{17}$. Ao isolar o pescador de sua cultura e de suas relações sociais e o peixe de seu ambiente, em paralelo à restrição da problemática

\footnotetext{
${ }^{16}$ O sistema de cotas não está previsto no conjunto de ordenamentos presentes no Plano de Gestão para pesca da tainha, mas tem sido defendido por alguns pesquisadores e organizações que participam dos debates em torno de sua gestão, calcados em uma perspectiva de sustentabilidade. Nas falas, são propostos pilotos ou mesmo modelagens em que a avaliação dos estoques estabeleceria as cotas para indústria e 'o que sobrar', como comentou um pesquisador, é calculado para pesca artesanal.

${ }_{17}$ Observamos que o documento se propõe a uma abordagem ecossistêmica e interdisciplinar, mas não há qualquer análise integrada seja em relação aos ambientes e a pressão exercida por outras atividades econômicas. Tampouco, as demais áreas do conhecimento científico são parte das metas a serem atingidas, contudo, restringe-se a análises descritivas e com proposições futuras, sem efeitos concretos nos regramentos propostos.
} 
ambiental ao regime de propriedade, tem se uma relação dicotômica perfeita: pescador versus natureza!A manutenção de um demanda o extermínio do outro!

A terceira dimensão volta-se a compreender - na relação entre o ciclo de vida da tainha com a pesca artesanal da Lagoa dos Patos e da pesca industrial catarinense - os elementos que dotados de um discurso de sustentabilidade se reverberam injustamente sobre os pescadores artesanais.

A tainha tem a maior parte de seu ciclo de vida em estuários. Seu deslocamento ao longo da costa ocorre devido ao período reprodutivo, caracterizado pelo início da maturação sexual no interior dos estuários e por estágios avançados no ambiente marinho. No outono inicia-se o período reprodutivo no interior do estuário, cujos exemplares ainda são jovens. As desovas - já com espécimes de maior tamanho - ocorrem no período do inverno. Após a desova, larvas e juvenis retornam aos estuários, permanecendo ali até a idade da primeira maturação. A tainha adulta que também não foi capturada retorna ao estuário após o período reprodutivo (MPA; MMA, 2015).

No Rio Grande do Sul a maior parte das tainhas capturadas pelos pescadores artesanais entre janeiro e agosto exibe tamanho superior ao da maturação da espécie, já em Santa Catarina, no primeiro semestre do ano há maior abundância de exemplares imaturos. O deslocamento da tainha, no período reprodutivo, ocorre em direção ao norte, podendo ser revertido ou suspenso conforme condições oceanográficas e climáticas (MPA; MMA, 2015).

Considerado o maior criadouro de tainhas, o estuário da Lagoa dos Patos tem suas tainhas deslocando para a costa, rumo ao norte, a partir de março. Áreas de desova estão situadas no litoral norte de Santa Catarina, quando em maio e junho ocorrem as desovas. Junho foi identificado como o principal mês de desova da espécie naquele estado (MPA; MMA, 2015).

No que tange à pesca industrial, a maior parte da frota atuante na captura da tainha é de Santa Catarina (70\% da frota permissionada em 2013), cuja pescaria é sazonal e ocorre na época de proibição da pesca de cerco da 
sardinha-verdadeira ${ }^{18}$. Na última década, sua importância aumentou devido ao mercado de exportação de ovas, que atualmente envolve três indústrias ${ }^{19}$ situadas neste mesmo estado. Ao caracterizarem as embarcações, verifica-se que $83 \%$ possuem tamanhos acima de 20 metros e $88 \%$ acima de 50 toneladas de arqueação bruta, constituindo embarcações de grande porte (MPA; MMA, 2015).

Outra pescaria relevante, também industrial, é a pesca de emalhe de superfície costeiro, que não possui limite para o número de embarcações permissionadas. Atualmente, conta com 487 embarcações, sendo 440 de Santa Catarina. Dados do Sindicato dos Armadores e Industrial da Pesca em Itajaí destacam que houve um incremento em $100 \%$ na captura de tainha nos anos de 2013 e 2014 (MPA; MMA, 2015).

Comércio relevante é o de ovas de tainha, dado que em 2014, $100 \mathrm{~g}$ da bottarga da tainha salgada e seca era comercializada por $\mathrm{R} \$ 79,90$ (U\$34,00). Já em 2012, o quilo de ovas de tainha no mercado externo era de $\bigcup \$ 20,00$ ( $R \$ 39,10)$, o dobro do ano anterior. Entre 2006 e 2013 foram exportadas em torno de 2.700 toneladas de ovas de tainha, gerando um montante de aproximadamente 48 milhões de dólares americanos. A estimativa é de que a renda média anual gerada pela pesca industrial é de trinta e cinco milhões de reais, sendo que 20 milhões são provenientes da comercialização de ovas (MPA; MMA, 2015).

Fora o período reprodutivo da tainha, quando ela é capturada ovada, as três empresas que se especializaram no comércio de ovas atuam sobre outros pescados e mantém-se em atividade, bem como, sua capacidade para extração de ovas é ociosa em aproximadamente $50 \%$. Relação esta que se caracteriza exclusivamente como um negócio contextualizado no mercado externo.

\footnotetext{
${ }^{18}$ Uma embarcação somente é permissionada para tainha se ela já atuar na captura de cerco de sardinha-verdadeira. Isso significa, na perspectiva da permissão pelo Estado, que a pesca industrial da tainha é caracterizada como uma atividade complementar, secundária e não principal. Azevedo \& Pierri (2014) destacam que o permissionamento para tainha, considerada sobrexplotada, ocorreu a partir do argumento que no período do defeso a indústria tornava-se ociosa, tendo sido assim, concedidas 89 permissões no período de 2003 a 2011, quando o considerado máximo sustentável pelos gestores ambientais era 60. Também destacam que as permissões foram dadas a embarcações com maior poder de pesca.

${ }^{19}$ No Plano constam quatro indústrias, mas quando do acompanhamento do debate sobre a gestão da tainha em Brasília, ao longo de 2017, foi nos informado que atualmente são três indústrias.
} 
Posto isto, destacamos o trecho do documento que aponta as distintas capacidades das pescarias que atuam sobre a captura da tainha:

\begin{abstract}
(...) considerando que um desembarque de uma traineira é da ordem de 10-30 t por viagem, que pode durar de 1-3 dias; que 0 desembarque do emalhe costeiro é da ordem de 1-3 t por viagem, de 1-3 dias; que o desembarque da pesca artesanal na Lagoa dos Patos é da ordem de 100-300 kg por desembarque e que a viagem dura de 1-2 dias e; que as despescas diárias de tainha dos pescadores desembarcados, na praia, variam em média de 1-12 kg. Conclui-se que o poder de pesca aumenta de uma ordem de magnitude, da pesca desembarcada na praia, para a pesca artesanal estuarina, dessa, para a pesca de média escala do emalhe costeiro, e dessa, para a pesca industrial das traineiras $(1-12 \mathrm{~kg}$ para $100-300 \mathrm{~kg}$; 1.000-3.000 kg; 10.000-30.000 kg), respectivamente (PERES, $2007 \mathrm{in}$ CEPSUL/IBAMA, 2007).O exposto demonstra que a atividade ocorre em um contexto multi-escalar, que compreende pescarias de subsistência, destinadas basicamente para o consumo; a de pequena escala ou artesanal que se destina ao consumo e comercialização local e regional e; a industrial orientada a abastecer os comércios locais, regionais e destinada à exportação. $O$ quadro demanda que $o$ Plano de Gestão defina as prioridades e os limites, considerando a importância econômica da tainha. Assim, o Plano de Gestão terá de lidar com questões de mercado, que prioriza a produção frente a qualquer outra questão, incluindo-se as de dimensões éticas, pois, qual a lógica de exportar ovas de uma espécie em situação de sobreexplotação e/ou de quase ameaça?(MPA; MMA, 2015, p. 139).
\end{abstract}

Exposto como parte do diagnóstico, tal questão deveria reverberar sobre o prognóstico proposto. Ou seja, contemplar a natureza multiescalar e o potencial de impactos socioambientais e a desigualdade social (e ambiental) das distintas pescarias, o que, como será destacado, não ocorreu.

Duas são as metas calcadas no argumento de sustentabilidade das pescarias e cujos regramentos são propostos para implantação imediata. A primeira volta-se à proteção da tainha no ambiente estuarino-lagunar. Dentre diversos regramentos, que reduzem a captura do pescado e que proíbem equipamentos de pesca utilizados na atualidade, destacamos: a proibição de uso de todos os tipos de redes, nas áreas estuarino-lagunares no período de $1^{\circ}$ de abril a 31 de maio (MPA; MMA, 2015, p. 168) e que tem demandado negociações ano a ano e mobilização dos pescadores(as) artesanais junto ao Ministério Público Federal, dada a eminência constante em se implementar a proibição.

A segunda meta visa garantir o sucesso da migração reprodutiva e da desova da plataforma e estabelece uma temporada anual de pesca onde destacamos a permissão: do cerco industrial, entre 15 de junho e 31 de julho; 
do emalhe costeiro de superfície: 15 de maio a 31 de julho. Posteriormente são estabelecidas áreas de pesca e o permissionamento para 50 cercos e 487 embarcações de emalhe costeiro, ambas da frota industrial ${ }^{20}$ (MPA; MMA, 2015, p. 172).

Destacamos que as novas medidas propostas inviabilizam a pesca artesanal no estuário da Lagoa dos Patos, ao mesmo tempo em que possibilitam o acesso irrestrito à tainha para pesca industrial. $O$ estuário da Lagoa dos Patos torna-se apenas uma reserva de mercado ou 'uma barriga de aluguel', como alega um dos pescadores indignado: no momento em que as tainhas iniciam o período de migração reprodutiva em direção ao norte até o deslocamento na costa catarinense, elas não podem ser pescadas.

É quando as mesmas concentram-se naquele litoral, entre 15 de junho e 31 de julho, há a temporada de pesca pela frota de cerco cujo poder de pesca é de 10 a 30 toneladas por viagem diária. E, entre 15 de maio e 31 de julho ocorre a temporada para o emalhe costeiro, cujo poder de pesca está entre $1 \mathrm{a}$ 3 toneladas por viagem diária.

O exercício em estimar os reflexos dos regramentos denota capturas na ordem de 44,5 mil toneladas por temporada de pesca ${ }^{21}$. Para fins de comparação, a pesca artesanal no estuário da Lagoa dos Patos captura na ordem de 216 a 780 toneladas por ano (FURG 2012, 2013, 2014, 2015), ou seja, entre $0,5 \%$ a $1,75 \%$ do poder de pesca estimado para frota industrial catarinense.

Interessante expor que enquanto a pesca artesanal para atender aos critérios de sustentabilidade a que se propõe o plano é sujeita a medidas de restrição de pesca, a frota industrial torna-se sustentável por meio de um

\footnotetext{
${ }^{20} \mathrm{O}$ emalhe costeiro, em especial, o emalhe anilhado é, por muitos, considerado uma pescaria artesanal. Contudo, sua capacidade de pesca é considerada na perspectiva dos gestores similar a uma frota industrial.

${ }_{21}$ Para esta estimativa assumiu-se que as embarcações de cerco capturam 10 toneladas/dia e as de emalhe costeiro 1 tonelada/dia e que elas ficaram dedicadas à pesca o período todo, exatamente pelo mesmo ser curto e ser aquele em que a espécie tem maior valor econômico.Ainda que os dados sejam uma estimativa do poder de captura e que não apenas a produtividade do ambiente como as condições oceanográficas e meteorológicas refletem na capacidade de captura, reitera-se que as demais pescarias estarão proibidas, estabelecendo uma "reserva de mercado" e possibilitando capturar o quanto estiver disponível.
} 
período de temporada de pesca ${ }^{22}$. Há uma inversão simbólica, não apenas de semântica onde a primeira é restrita e a segunda incentivada!

Corroboramos as análises de Valencio (2010) sobre os pescadores artesanais no Rio São Francisco, que aponta os agentes da modernidade como os principais responsáveis pelas mudanças das relações dos povos tradicionais do seu território.

$\mathrm{Na}$ racionalização instrumental, o mercado e o Estado constroem conjuntamente uma ação estratégica para deflagrar a desterritorialização dos pescadores artesanais por meio da obstaculização crescente do acesso aos mananciais [...]. Os rios e as águas como espaço e um bem público, passaram a ser mais explicitamente interditados aos pescadores por um arcabouço legal oriundo da interpenetração do interesse econômico [...], nos meandros da administração pública exercida personalisticamente (VALENCIO, 2010, p. 205).

E também sobre uma ciência que contribui à construção de uma visão dicotômica entre sociedade e ambiente que nega aos pescadores artesanais seus direitos, ainda que enrustida de cordialidade.

Logo, a performatividade com que a burocracia ambiental lançava o arcabouço legal para que o descarte dos direitos da pesca artesanal fosse indiscutível, implicava ter cientistas dispostos a municiar 0 argumento de que esse modo de vida é destituído de um valor intrínseco(VALENCIO, 2010, p. 205).

\section{Considerações Finais}

As reflexões aqui expostas denotam que os regramentos ambientais propostos para gestão da pesca da tainha ignoram outras racionalidades. Os agentes do estado, em articulação com uma ciência que isola o peixe de seu ambiente e os pescadores de sua dinâmica socioeconômica, definem regras

\footnotetext{
${ }^{22}$ Ao acompanharmos as discussões para o ordenamento da tainha no ano de $2017 \mathrm{em}$ Brasília/DF, por meio do convite para participação da Reunião do Grupo Gestor de Recursos Pelágicos, de natureza consultiva e do qual não há representação dos pescadores artesanais do Rio Grande do Sul, verificamos a proposição em diminuição do número de barcos para pesca de cerco. Essa frota, contudo, não possui limites de tamanho, tampouco limite de captura/barco. Também não há qualquer mecanismo que evite a concentração de embarcações/permissão por pessoa física ou jurídica. Assim, associada à proibição da pesca artesanal nos meses anteriores nos estuários, verifica-se maior facilidade de captura por parte da indústria, em viagens de pesca mais próximas aquele estado. Também se destaca, que a despeito das restrições propostas por meio de portarias desde 2015, os empresários ganham na justiça o direito de pescar, fato que faz com que atualmente, na prática, haja o mesmo quantitativo de embarcações industriais. Já os pescadores artesanais não dispõem de tais mecanismos, e ao terem sua atividade restrita tornam-se alvos de fiscalização. As distintas relações de poder econômico e político não são consideradas na elaboração do plano, corroborando com a ideia de que tanto os impactos da medida como o impacto da falta delas, na ausência de pescado, tem consequências similares para todos os pescadores.
} 
investidas de sustentabilidade que nada tem de sustentável e que nega, aos pescadores artesanais do estuário da Lagoa dos Patos, a manutenção do seu modo de vida.

No caso apresentado, verifica-se que a centralidade do regramento ambiental é ancorada em uma disciplina: a biologia pesqueira. Unidade de gestão, Regime de Propriedade e Ciclo de Vida - elementos centrais a esta concepção de mundo pautada no paradigma da adequação - são utilizados na concepção de uma gestão pesqueira estado-centrada que nega a participação daqueles que têm na pesca artesanal sua produção econômica e sua reprodução social.

Não significa, contudo, que apenas esta área do conhecimento estabelece uma racionalidade que ignora o conhecimento tradicional e se constitui como conhecimento absoluto. Distintas áreas do conhecimento podem apresentar a mesma lógica, demandando compreender como a Ciência ao se constituir hegemonicamente enquanto forma de conhecimento, nega outros saberes e, até mesmo, o direito a reprodução social de determinados grupos sociais.

Ao explicitarmos um caso de injustiça ambiental, argumentamos sobre a necessidade da Ciência e da Gestão Pesqueira em, ao atuarem na perspectiva da sustentabilidade, compreenderem outras racionalidades distintas do pensamento dicotômico acerca da relação sociedade e ambiente.

\section{Referências bibliográficas}

ACSELRAD, Henry. Ambientalização das lutas sociais. O caso do movimento por justiça ambiental. Estudos Avançados, 24 (68), 103-119, 2010.

Conflitos Ambientais no Brasil. Fundação Heinrich Böll, 2004.

AZEVEDO, Natália .T. de; PIERRI, Naína. A política pesqueira no Brasil (20032011): a escolha pelo crescimento produtivo e o lugar da pesca artesanal. Desenvolvimento e Meio Ambiente. v. 32, p.61-80, 18 dez. 2014.

BRASIL. Constituição da República Federativa do Brasil (1988): texto constitucional promulgado em 5 de outubro de 1988, com as alterações adotadas pelas Emendas Constitucionais no 1/92 a 38/2002 e pelas Emendas Constitucionais de Revisão no 1 a 64/94. Brasília: Senado Federal, Subsecretaria de Edições Técnicas. Brasília: Senado Federal, 2002. 
Instrução Normativa Conjunta entre MMA/SEAP - IN no 03 de 09 de Fevereiro de 2004, Publicada no DOU em 11/02/2004

Decreto no 6.981, de 13 de outubro de 2009. Regulamenta o art. 27, $\S 60$, inciso I, da Lei no 10.683 , de 2003 , dispondo sobre a atuação conjunta dos Ministérios da Pesca e Aquicultura e do Meio Ambiente nos aspectos relacionados ao uso sustentável dos recursos pesqueiros. Publicado no DOU em 14.10.2009

Portaria MPA/MMA no 03, de 14 de Maio de 2015. Aprovar o Plano de Gestão para o Uso Sustentável da Tainha, Mugil liza, nas regiões Sudeste e Sul do Brasil. DOU 15/05/2015, Seção 1, p.24.

DIEGUES, Antônio C. S. Pescadores, Camponeses e Trabalhadores do Mar. São Paulo/SP: Editora Atica, 292p., 1983.

\& ARRUDA, Rinaldo. S. V. (orgs.). Saberes tradicionais e biodiversidade no Brasil. Brasília: MMA; São Paulo: USP, 2001.

FAO. The State of World Fisheries and Aquaculture.Contributing to food security and nutrition for all. ROMA: FAO - Food Agriculture Organization, 2016.

FREITAS, Carlos. M. DE. Ciência para a sustentabilidade e a justiça ambiental. In: ACSELRAD, Henry; HERCULANO, Selene; PÁDUA, José. A. (Org.) Justiça Ambiental e Cidadania. Niterói/RJ: Editora UFF, $2^{a}$ Edição, p.141-158, 2004.

FURG. Boletim Estatístico da Pesca Marinha e Estuarina do sul do Rio Grande do Sul,38p., 2012.

FURG. Boletim Estatístico da Pesca Marinha e Estuarina do sul do Rio Grande do Sul. 54p., 2013.

FURG. Boletim Estatístico da Pesca Marinha e Estuarina do sul do Rio Grande do Sul. 78p., 2014.

FURG. Boletim Estatístico da Pesca Marinha e Estuarina do sul do Rio Grande do Sul. 78p., 2015.

HELLEBRANDT, Luceni. M.; RIAL, Carmem. S.; LEITÃO, Maria do Rosário. De F. A. Pesca e Gênero: Reconhecimento Legal e Organização das Mulheres na "Colônia Z3" (Pelotas/RS - Brasil). Vivência: Revista de Antropologia, 47, v. 1, n. Dossiê Pesca: populações costeiras e ribeirinhas, 123-136, 2016

HERCULANO, Selene. O CLAMOR POR JUSTICCA AMBIENTAL E CONTRA O RACISMO AMBIENTAL. INTERFACEHS - Revista de Gestão Integrada em Saúde do Trabalho e Meio Ambiente, v. 3, n. 1, p. 1-20, 2008.

KALIKOSKI, Daniela. C.; VASCONCELLOS, Marcelo. Estudo das condições técnicas, econômicas e ambientais da pesca de pequena escala no estuário da Lagoa dos Patos, Brasil: uma metodologia de avaliação. FAO Fisheries and Aquaculture Circular No. 1075. Rome, FAO. 200 pp, 2013. 
LEFF, Enrique. Racionalidade ambiental:a reapropriação social da natureza / Enrique Leff, tradução Luís Carlos Cabral. - Rio de Janeiro: Civilização Brasileira, 2006.

MINAYO, Maria Cecília DE S.; ASSIS, Simone G. DE; SOUZA, Edinilsa R. DE. Avaliação por triangulação de métodos: abordagem de programas sociais. Editora Fiocruz, 2005.

MPA; MMA. PLANO DE GESTÃO PARA O USO SUSTENTÁVEL DA TAINHA, Mugi lliza Valenciennes, 1836, NO SUDESTE E SUL DO BRASIL. 2015

THIOLLENT, Michel. T. Metodologia da pesquisa-ação. Cortez Editora, 2007.

UEMA, Elisabeth. Controle Social, Saber Perito e Participação. IN: LOUREIRO, Carlos Frederico B. Educação Ambiental no Contexto das Medidas Mitigadoras e Compensatórios de Impactos Ambientais: a Perspectiva do Licenciamento. Salvador/BA: Instituto de Meio Ambiente - IMA, Série Educação Ambiental, v.50, 51-80, 2009.

VALENCIO, Norma. Conflitos Ambientais no Velho Chico: o modus operandi da desacreditação pública da pesca artesanal. In: ZHOURI, Andréa.; LASCHEFSKI, Klemens. Desenvolvimento e Conflitos Ambientais. Belo Horizonte/MG: Editora UFMG, $1^{\text {a }}$ Edição ed., p.202-223, 2010. 